\title{
PREVALENNCIA DE ANTICORPOS CONTRA ARBOVÍRUS DA FAMÍLIA Bunyaviridae EM BÚFALOS DE ÁGUA
}

\section{PREVALENCE OF ARBOVIRUS ANTIBODIES AGAINST THE FAMILY Bunyaviridae IN WATER BUFFALOES}

\author{
Alexandre Rosário Casseb ${ }^{1^{*}}$ \\ Sandro Patroca Silva ${ }^{1}$ \\ Livia Medeiros Neves Casseb² \\ Jannifer Oliveira Chiang ${ }^{3}$ \\ Lívia Carício Martins ${ }^{3}$ \\ Pedro Fernando Costa Vasconcelos ${ }^{3}$ \\ 1 Universidade Federal Rural da Amazônia, Departamento de Patologia e Medicina Veterinária Preventiva, \\ Belém, PA, Brasil. \\ 2Universidade Federal do Pará, Belém, PA, Brasil \\ 3Instituto Evandro Chagas, Seção de Arbovirologia e Febres Hemorrágicas, Ananindeua, PA, Brasil \\ *Autor para correspondência - alexcasseb@yahoo.com.br
}

\section{Resumo}

O Estado do Pará corresponde a $26 \%$ da Amazônica brasileira, onde uma grande quantidade de Arbovírus tem sido descrito. O presente trabalho teve como objetivo determinar a prevalência de anticorpos detectados pela técnica de inibição de hemaglutinação contra nove tipos diferentes de arbovírus da família Bunyaviridae, sendo oito do gênero Orthobunyavirus: vírus Guaroa, vírus Maguari, vírus Tacaiuma, vírus Utinga, vírus Belem, vírus Caraparu, vírus Oropouche e vírus Catu e um do gênero Phlebovirus: vírus Icoaraci, em soros de búfalos de água no Estado do Pará, Brasil. Para todos os Arbovírus investigados houve presença de anticorpos, com exceção do vírus Belém. Anticorpos para o vírus Maguari foram mais prevalentes (7,33\%). O rebanho bubalino do presente estudo mostrou variáveis níveis de anticorpos em reações heterotípicas e monotípicas podendo indicar que há circulação da maioria dos bunyavírus estudados em búfalos domésticos no estado do Pará, e que o vírus Maguari é o de maior circulação. Por isso, são necessários outros estudos para investigar o papel dos búfalos de água na manutenção e dispersão de arbovírus, assim como se esses vírus podem causar enfermidades na referida espécie, principalmente, em casos de defeitos congênitos e abortamentos.

Palavras-chave: Bubalus bubalis; Bunyaviridae; Teste de Inibição da Hemaglutinação; vírus Maguari.

\footnotetext{
Abstract

The State of Pará comprises $26 \%$ of Brazilian Amazon region where a large diversity of arboviruses has been described. This study sought to assess the prevalence and distribution of haemagglutination-inhibition antibodies against antigens of nine different types of arbovirus of the
} 
Bunyaviridae family, where eight were Orthobunyavirus: Guaroa virus, Maguari virus, Tacaiuma virus, Utinga virus, Belem virus, Caraparu virus, Oropouche virus and Catu virus, and one Phlebovirus: Icoaraci virus in sera samples of water buffaloes in Pará State, Brazil. For all Arboviruses investigated there were antibodies, with the exception of Belem virus. Antibodies to Maguari virus were more prevalent $(7.33 \%)$. The water buffaloes of the present study showed variable levels of antibodies in monotypic and heterotypic reactions that may indicate there are movements from most bunyavirus studied in domestic buffaloes in the state of Pará, and the Maguari virus presents the largest circulation. Therefore, further studies are needed to investigate the role of water buffalo in the maintenance and dispersal of arboviruses, as well as whether these viruses can cause disease in that species, especially in cases of birth defects and abortions.

Keywords: Bubalus bubalis; Bunyaviridae; Haemagglutination Inhibition Test; Maguari virus.

Recebido em: 06 novembro 2011

Aceito em: 06 janeiro 2015

\section{Introdução}

Em 1942 a expressão arthropod-borne virus foi adotada para classificar um grupo de vírus de animais que se propagam em artrópodes e são transmitidos biologicamente aos hospedeiros vertebrados. Duas décadas depois, o Subcomitê Internacional para Nomenclatura Viral recomendou a adoção oficial do termo arbovirus (arbovírus) para designação dos vírus que são mantidos em natureza em ciclos envolvendo vetores artrópodes hematófagos e hospedeiros vertebrados ${ }^{(1)}$.

A família Bunyaviridae constitui a maior família dos vírus de ácido ribonucléico (RNA), possuindo o maior número de arbovírus conhecidos, com aproximadamente 305 tipos distribuídos em cinco gêneros: Orthobunyavirus (172 entre espécies, subtipos, espécies tentativas e vírus não grupados), Nairovirus (34 entre espécies, sorogrupos e tipos), Phlebovirus (52 entre espécies, espécies tentativas, tipos e subtipos virais), Tospovirus (14 entre espécies e espécies tentativas) e Hantavirus (24 espécies), afora 41 espécies e grupos não classificados em gêneros na família Bunyaviridae e 23 sorotipos não classificados e não agrupados. Ressalta-se que os vírus do gênero Tospovirus são vírus de insetos e os vírus do gênero Hantavirus são vírus de roedores e não são considerados arbovírus $^{(2)}$.

O gênero Orthobunyavirus apresenta os seguintes arbovírus que causam doença em animais domésticos: Vírus Akabane (AKAV), Vírus do Cache Valley (CVV), Vírus da febre hemorrágica da Crimean-Congo (CCHFV), Vírus aino (AINV) e Vírus peaton (PEAV); o gênero Nairovirus apresenta arbovírus Vírus da doença dos ovinos de Nairobi (NSDV), que causa doença em animais domésticos; e o gênero Phlebovirus que apresenta arbovírus Vírus da febre do Rift Valley (RVFV), que causa doença em animais domésticos. Esses arbovírus manifestam principalmente quadro de abortamento e anomalias congênitas, assim como casos de gastrenterite hemorrágica nos animais doentes $^{(3)}$; no entanto, não há descrições da circulação desses arbovírus na América do Sul ${ }^{(4)}$.

A família Bunynaviridae apresenta dez sorogrupos, com representantes isolados em animais silvestres ou mosquitos hematófagos na Amazônia brasileira, que são: Grupo $\mathrm{C}$ (ex. vírus Caraparu-CARV), Grupo Anopheles A (ex. vírus Tacaiuma-TCMV), Grupo Bunyamwera (ex. vírus Maguari-MAGV), Grupo California (ex. vírus Guaroa-GROV), Grupo Capim (ex. vírus 
Capim), Grupo Gamboa (ex. vírus Gamboa), Grupo Guama (ex. vírus Catu-CATUV), Grupo Pacora, Grupo Simbu (ex. vírus Oropouche-OROV e vírus Utinga-UTIV) e Grupo Turlock, assim como vários vírus não agrupados. O gênero Phlebovirus apresenta um único grupo denominado Phlebotomus Fever (ex. vírus Icoaraci-ICOV), com 22 tipos diferentes ${ }^{(5)}$. Não há relato de enfermidades em animais domésticos relacionadas com arbovírus da família Bunyaviridae no território brasileiro, apesar de haver algumas enfermidades humanas. A circulação dos vírus desta família já fora identificada em animais silvestres na Amazônia Brasileira ${ }^{(5)}$.

A floresta amazônica é uma das maiores reservas de arbovírus do mundo, não só devido às condições climáticas favoráveis, mas também à grande diversidade da fauna e flora, com abundante variedade de artrópodes hematófagos e vertebrados silvestres, que constituem os elementos fundamentais para a manutenção desses vírus e o estado do Pará, com $1.248 .042 \mathrm{~km}^{2}$ de extensão, representa 16,66\% do território brasileiro e $26 \%$ da Amazônia brasileira; é cortado pela linha do Equador no seu extremo norte, sendo dividido em 144 municípios, onde vivem cerca de seis milhões de pessoas ${ }^{(6)}$.

Dos arbovírus registrados no Catálogo Internacional são conhecidos aproximadamente cem que infectam humanos e quarenta que infectam animais domésticos. Alguns desses arbovírus causam somente infecções subclínicas detectadas pela presença de anticorpos ${ }^{(1)}$. Tais infecções não provocam um efeito evidente na saúde, mas podem indicar que um arbovírus está circulando e que os animais com viremia podem servir de fonte de infecção para vetores artrópodes hematófagos ${ }^{(7)}$. Por até onde se sabe, não existem registros de estudos sobre búfalos de água voltados para investigar a prevalência de anticorpos nem avaliação sobre o possível papel que esses animais desempenham no ciclo de manutenção e sua importância na dispersão de arbovírus da família Bunyaviridae e este foi o direcionamento deste estudo.

\section{Material e Métodos}

O presente trabalho foi aprovado pela Comissão de Ética no Uso de Animais (CEUA) do Instituto Evandro Chagas (IEC), sob o número 054/2009 CEPAN/IEC. Neste estudo, as mesorregiões foram agrupadas em três macrorregiões: Nordeste, composta pelas mesorregiões do Marajó, Metropolitana de Belém e Nordeste Paraense propriamente; Oeste, composta pelas mesorregiões do Baixo Amazonas e Sudoeste Paraense; e Sudeste, composta pela mesorregião do Sudeste Paraense.

O sangue dos animais foi obtido em 2009 nas seis mesorregiões do estado do Pará, conforme descrição a seguir: Mesorregião do Baixo Amazonas (100), nos municípios de Santarém, Prainha e Alenquer; Mesorregião do Marajó (154), nos municípios de Salvaterra e Soure; Mesorregião Metropolitana de Belém (100), nos municípios de Belém, Castanhal e Bujaru; Mesorregião do Sudoeste Paraense (100) nos municípios de Altamira, Brasil Novo e Vitória do Xingu; Mesorregião do Sudeste Paraense (100), nos municípios de Redenção, Paragominas, Tucuruí e Xinguara; e Mesorregião do Nordeste Paraense (100), nos municípios de Nova Timboteua, Capitão Poço, Capanema, Tailândia, Tomé-Açu, Peixe Boi, Bragança e Ipixuna do Pará (Figura 1).

A coleta foi por punção venosa jugular a vácuo, sem uso de anticoagulante, e os animais submetidos à sangria eram búfalos de água (Bubalus bubalis), independente de sexo ou raça. Foram obtidas 654 amostras de animais adultos (idade superior a dois anos), nascidos e criados na região. Após a adequada contenção do animal e assepsia local. O sangue colhido, de 5 a $10 \mathrm{~mL}$, foi deixado em 
repouso por cerca de 90 minutos para a coagulação e separação do soro e, em seguida, submetido à centrifugação a $2.000 \mathrm{xg}$ por 5 minutos. O soro separado foi transportado em gelo e posteriormente armazenado a $-70{ }^{\circ} \mathrm{C}$ até a realização do teste sorológico.

O teste de inibição de hemaglutinação (IH) foi realizado de acordo com o protocolo adaptado para microplacas descrito por Shope ${ }^{(8)}$. O teste foi realizado usando-se antígenos de arbovírus isolados no Brasil, em um painel constituído de nove tipos diferentes de arbovírus (Tabela 1), pertencentes ao acervo da Seção de Arbovirologia e Febres Hemorrágicas do Instituto Evandro Chagas, Ananindeua-PA, Brasil. Esses antígenos foram preparados a partir de cérebros, fígados ou soros infectados de camundongos recém-nascidos, pela técnica de extração por sucrose-acetona, e os soros foram testados (diluição inicial 1:20) contra 4 unidades dos antígenos ${ }^{(9)}$.

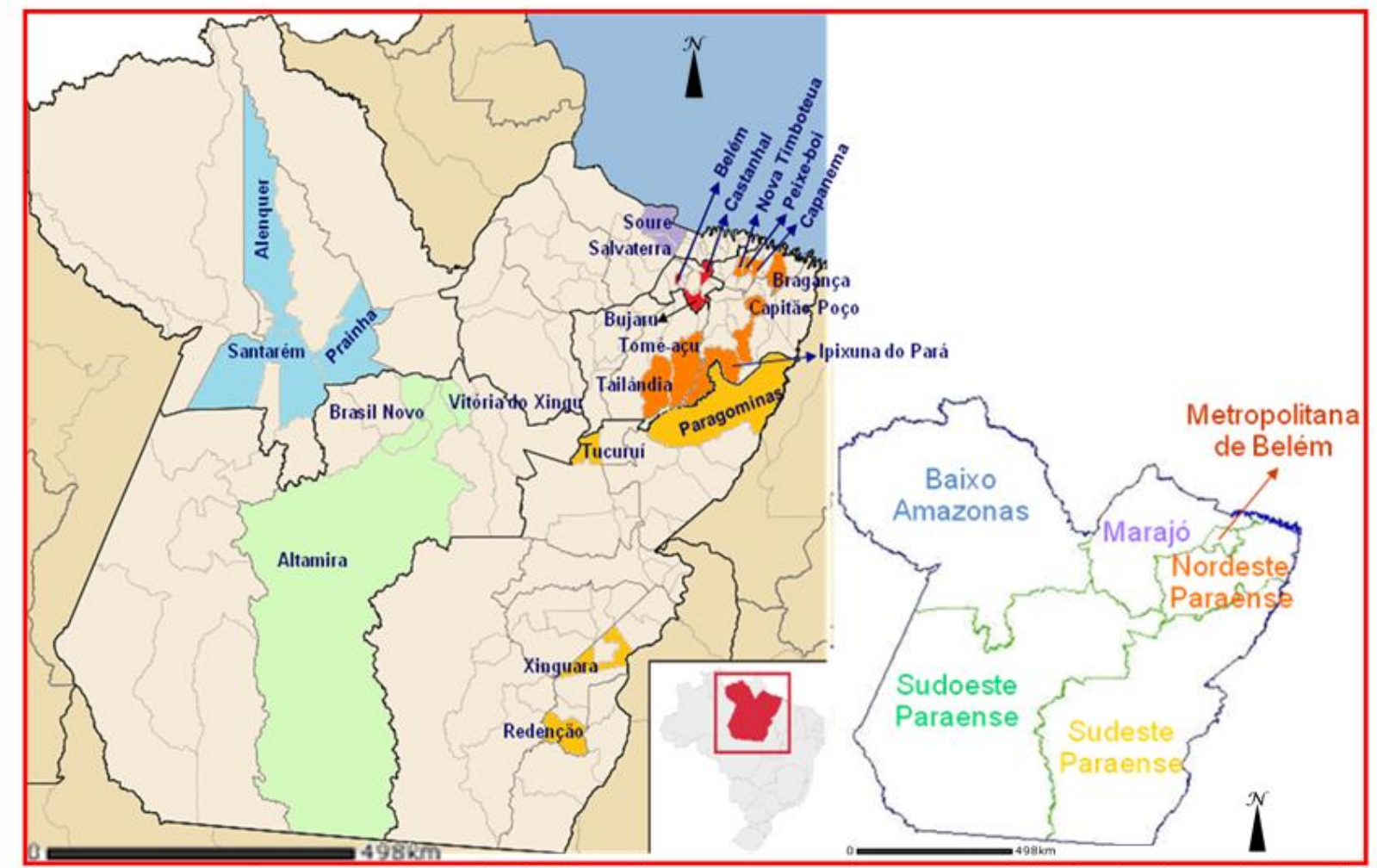

Figura 1- Mapa do estado do Pará, indicando as mesorregiões e Municípios da área de estudo em búfalos de água, Brasil, 2009.

Fonte: Adaptado de IBGE (Instituto Brasileiro de Geografia e Estatística) Divisao_MAPAS33441148189. [2006b] Banco de dados agregados. Sistema IBGE de recuperação automática - SIDRA. Disponível em $\langle\mathrm{http}: / /$ www.sidra.ibge.gov.br>, Acesso em 10/10/2013.

O critério de positividade foi o recomendado por Rodrigues et al. ${ }^{(10)}$, sendo as reações positivas classificadas como monotípicas (quando a reatividade ocorreu para apenas um antígeno ou reação para um dos antígenos foi pelo menos 4 vezes maior que para os demais antígenos de membros do mesmo gênero viral), heterotípicas (quando a reatividade para antígenos de um mesmo gênero de vírus demonstrou títulos semelhantes ou o predomínio para um dado antígeno foi menor que 4 vezes os demais) e reações totais (reações monotípicas e heterotípicas).

Os resultados foram tabulados e confrontados pelo teste do Qui-quadrado de aderência, cujos escores amostrais foram mensurados admitindo-se nível de significância $(\alpha)$ de 0,05 para rejeição da hipótese de nulidade $(p \leq \alpha)$ implementado pelo programa BioEstat 5.0 $0^{(11)}$. 
Tabela 1: Antígenos de nove tipos diferentes de arbovírus da família Bunyaviridae isolados no Brasil e pertencentes ao acervo da Seção de Arbovirologia e Febres Hemorrágicas do Instituto Evandro Chagas, Ananindeua-PA, Brasil

\begin{tabular}{lll}
\hline Gêneros & \multicolumn{1}{c}{ Antígenos Virais } & \multicolumn{1}{c}{ Cepa } \\
\hline & virus Guaroa (GROV) & Be H 22063 \\
virus Maguari (MAGV) & Be AR 7272 \\
virus Tacaiuma (TCMV) & Be AN 73 \\
& virus Utinga (UTIV) & Be AN 84785 \\
& virus Belem (BLMV) & Be AN 141106 \\
Orthobunyavirus & virus Caraparu (CARV) & Be AN 3994 \\
& virus Oropouche (OROV) & Be AN 19991 \\
& virus Catu (CATUV) & Be H 151 \\
\hline Phlebovirus & virus Icoaraci (ICOV) & Be AN 24262 \\
\hline
\end{tabular}

\section{Resultados e Discussão}

No presente estudo, foi determinada a prevalência de anticorpos IH para nove tipos de vírus da família Bunyaviridae em búfalos de água. Foram detectados anticorpos contra oito arbovírus analisados e não houve positividade para o Vírus Belém (Tabela 2). Na mesorregião Metropolitana de Belém não houve detecção de anticorpos para o ICOV e OROV; na mesorregião do Nordeste Paraense não foram detectados anticorpos para o OROV; na mesorregião do Sudeste Paraense não foram encontrados anticorpos nos animais analisados para o CARV. O encontro dessas reações para os vírus estudados comprova a circulação desses arbovírus da família Bunyaviridae no estado do Pará, Amazônia brasileira, em búfalos de água.

Esses achados, em búfalos de água, são importantes, pois são raras as evidências incriminando esses animais às infecções por arbovírus, embora esses vírus encontrem condições favoráveis à sua manutenção em natureza dada a grande biodiversidade na região Amazônica do Brasil e o hábito da espécie que vive em terras alagadas onde há grande número de insetos hematófagos. É interessante notar, também, que a positividade estava presente muitas vezes para diferentes vírus em um mesmo soro animal (reações heterotípicas), sugerindo que estes se infectaram por mais de um arbovírus, assim como um elevado número de reações monotípicas demonstrando infecção por um único vírus.

As enfermidades causadas por arbovírus da família Bunyaviridae em animais domésticos que causam, principalmente, abortamento com anomalias congênitas, diferem das doenças causadas pelos arbovírus da família Togaviridae e Flaviviridae, que causam síndromes sistêmicas, encefálicas ou hemorrágicas $^{(1)}$. Os agentes virais são importantes causadores de abortamento em bovinos e anomalias congênitas ${ }^{(12,13)}$. 
Tabela 2: Distribuição da prevalência de anticorpos IH para antígenos de nove arbovírus da família Bunyaviridae de soro de búfalos de água com reações heterotípicas, reações monotípicas e reações totais, Estado do Pará, Brasil, 2009

\begin{tabular}{lllllll}
\hline \multicolumn{7}{c}{ Búfalos de água } \\
N=654 \\
\hline Vírus & RH & \%RH & RM & \%RM & RT & \%RT \\
\hline GROV & 01 & 0,15 & 06 & 0,91 & 07 & 1,07 \\
MAGV & 05 & 0,76 & 43 & 6,64 & 48 & 7,33 \\
TCMV & 01 & 0,15 & 08 & 1,22 & 09 & 1,37 \\
ICOV & --- & --- & 15 & 2,33 & 15 & 2,33 \\
UTIV & --- & --- & 03 & 0,45 & 03 & 0,45 \\
BLMV & --- & --- & --- & --- & --- & -- \\
CARV & --- & --- & 06 & 0,91 & 06 & 0,91 \\
OROV & 02 & 0,30 & 01 & 0,15 & 03 & 0,45 \\
CATUV & 01 & 0,15 & 06 & 0,91 & 07 & 1,07 \\
\hline
\end{tabular}

RH- Reações heterotípcas; RM- Reações monotípicas; RT- Reações totais; GROV- vírus Guaroa; MAGV- vírus Maguary; TCMV- virus Tacaiuma; ICOV- vírus Icoaraci; UTIV- vírus Utinga; BLMV- vírus Belem; CARVvírus Caraparu; OROV- vírus Oropouche; CATU- vírus Catu.

O MAGV é antigenicamente relacionado com os arbovírus CVV, KRIV e $\mathrm{MDV}^{(6,18)}$, que são sabidamente causadores de febre, abortos, anomalias congênitas e encefalites em animais na América do Norte (CVV e MDV) e América do Sul e Central (KRIV), já foi isolado de equinos na Guiana Francesa $^{(19)}$ e Colômbia ${ }^{(20)}$, bem como foi descrita imunidade em búfalos, equinos, ovinos e bovinos e em humanos no Brasil e Argentina ${ }^{(1,21)}$. O MAGV foi o vírus com maior prevalência de anticorpos IH neste estudo e reforça-se a necessidade de que novos estudos sejam realizados para determinar a sua patogênese nesses animais assim como sua importância epidemiológica. Em um estudo realizado no pantanal brasileiro, Iversson et al. ${ }^{(22)}$ encontraram anticorpos neutralizantes para o MAGV em $28 \%$ dos equinos testados e Monath et al. ${ }^{(15)}$, em estudo conduzido em equinos da Argentina, obtiveram uma prevalência de anticorpos neutralizantes de $80 \%$ para o MAGV, sem, porém, terem sido registradas epidemias de encefalites ou ocorrência de defeitos congênitos por esse arbovírus.

O CVV pertence ao sorogrupo Bunyamwera, está associado a defeitos congênitos de ovinos em rebanhos na América do Norte ${ }^{(14)}$ e já foi isolado de um equino com encefalite nos EUA ${ }^{(15)}$. Um arbovírus isolado de um equino febril na Argentina foi identificado como Kairi virus (KRIV), também, pertencente ao sorogrupo Bunyamwera ${ }^{(16)}$. O arbovírus Main Drain virus (MDV) também já foi isolado de equinos com encefalite na Califórnia, $E A^{(17)}$ e ovelhas gestantes inoculadas experimentalmente produziram teratogênese ${ }^{(18)}$.

O RVFV é causa importante de doença humana e apresenta importância considerável na mortalidade de animais recém-nascidos; é também causa de abortos em animais domésticos em especial em ovinos, bovinos e bubalinos, sendo endêmico no sul e leste da África ${ }^{(23)}$. Esse arbovírus do gênero Phlebovirus é relacionado geneticamente ao ICOV, que apresentou a segunda maior prevalência de anticorpos $\mathrm{IH}$ em reações totais $(2,33 \%)$ no presente estudo. O ICOV foi isolado pela primeira vez em roedores silvestres em uma floresta próxima a Belém, Estado do Pará, em 1960, e anticorpos IH são frequentemente detectados em pequenos animais da floresta, 
especialmente roedores, porém, não tem sido encontrado na população humana de Belém ${ }^{(24)}$. Destaca-se que não foram detectados anticorpos nos búfalos no município de Belém no presente estudo. Os demais arbovírus da família Bunyaviridae apresentaram baixa prevalência de anticorpos IH nos búfalos de água analisados neste estudo.

No presente estudo, foram analisados anticorpos IH para dois arbovírus do Grupo Simbu, que ainda não foram associados como causadores de doença em animais domésticos. Esses arbovírus apresentaram reações monotípicas que incluíram o UTIV e o OROV, porém com uma prevalência abaixo de 1\%. Os AKAV, AINV e PEAV acometem bovinos e ovinos, pertencem ao sorogrupo Simbu, ocorrem em regiões tropicais e subtropicais do Velho Mundo e estão associados a defeitos congênitos (artrogripose e hidrocefalia) e abortamento em animais domésticos ${ }^{(3,25,26)}$. Surtos de artrogripose e hidrocefalia em bovinos na Austrália foram associados ao encontro de altos títulos de anticorpos IH para o $\mathrm{AKAV}^{(27)}$; entretanto, casos de infecção pelo AKAV ainda não foram relatados no Brasil ${ }^{(28)}$. Por outro lado, estudos prévios realizados no Brasil sobre defeito congênito, como artrogripose, em fetos abortados de bovinos e ovinos demonstram ausência de um agente etiológico específico ${ }^{(29)}$. Sendo assim, há necessidade de pesquisas com outros agentes etiológicos que possam causar abortamento e anomalias congênitas e que ainda não tenham sido relatados.

\section{Conclusões}

Os resultados de estudos sorológicos como este resultam em conhecimento da prevalência dos arbovírus da família Bunyaviridae de maior circulação em búfalos de água no estado do Pará, sendo de fundamental importância para a Saúde Pública, pois esses animais em geral são hospedeiros finais e, em alguns casos, podem servir como fonte de amplificação desses arbovírus, como possível fonte de infecção. Por isso, são necessários outros estudos para investigar o papel dos búfalos de água na manutenção e dispersão de arbovírus, assim como se esses vírus podem causar enfermidades na referida espécie, principalmente, em casos de defeitos congênitos e abortamentos dos quais não se sabe a etiologia. Finalmente, é importante investigar a ocorrência de epizootias e ou de possíveis epidemias que afetem o homem e búfalos de água por arbovírus, principalmente pelo MAGV que apresentou maior prevalência.

\section{Referências}

1. CASSEB AR, CASSEB LMN, SILVA SP, VASCONCELOS PFC. Arbovírus: importante zoonose na Amazônia brasileira. Vet. e Zootec. 2013 set.; 20(3) Disponível em: <www.fmvz.unesp.br/rvz/index.php/rvz/article/download/191/461 >. Acesso em novembro de 2014.

2. International Committee on Taxonomy of Viruses (ICTV). ICTV Master Species Listi 2014 v3. Disponível em:< http://ictvonline.org/virustaxonomy.asp. > . Acesso em novembro de 2014.

3. St George TD, Standfast HA, Cybinski DH, Filippich C, Carley JG. Peaton virus: a new simbu group arbovirus isolated from cattle and Culicoides brevitarsis in Australia. Aust J Biol Sci. 1980; 33: 235-43.

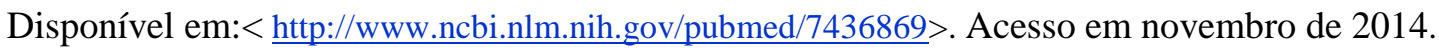

4. Kirkland PD. Akabane and Bovine ephemeral fever virus infections. Veterinary Clinical of North America and Food Animal Practical, 18: 501-14, 2002. Disponível em: <http://www.ncbi.nlm.nih.gov/pubmed/12442580>. Acesso em novembro de 2014.

5. Travassos da Rosa JFS, Travassos da Rosa APA, Vasconcelos PFC, Pinheiro FP, Rodrigues SG, 
Travassos da Rosa ES, et al. Arboviruses isolated in the Evandro Chagas Institute, including some decribed for the first time in the Brazilian Amazon region, their known hosts, and their pathology for man. In: Travassos da Rosa APA, Vasconcelos PFC, Travassos da Rosa JFS, editores. An Overview of Arbovirology in Brazil and Neighbouring Countries. Belém: Instituto Evandro Chagas; 1998. p.19-31. Disponível em: $\langle$ http://iah.iec.pa.gov.br/iah/fulltext/pc/monografias/iec/overview/overview02p18-31.pdf>. Acesso em novembro de 2014.

6. Vasconcelos PFC, Travassos da Rosa APA, Dégallier N, Travassos da Rosa JFS, Pinheiro FP. Clinical and ecoepidemiological situation of human arboviruses in Brazilian Amazonia. Ciência e Cultura (Journal of the Brazilian association for the Advancement of Science), 44: 117-124, 1992. Disponível em: $\langle$ http://horizon.documentation.ird.fr/exl-doc/pleins_textes/pleins_textes_6/b_fdi_33-34/38273.pdf >. Acesso em novembro de 2014.

7. Vasconcelos PFC, Travassos da Rosa APA, Rodrigues SG, Travassos da Rosa ES, Dégallier N, Travassos da Rosa JFS. Inadequate management of natural ecosystem in the Brazilian Amazon region results in the emergence and reemergence of arboviruses. Cadernos de Saúde Pública, 17: 155-164, 2001. Disponível em: $<$ http://www.scielosp.org/scielo.php?script=sci_arttext\&pid=S0102-

311X2001000700025\&lng=en\&nrm=iso\&tlng=en>. Acesso em novembro de 2014.

8. Shope RE. The use of micro-hemagglutination-inhibition test to follow antibody response after arthropodborne virus infection in a community of forest animals. Anais de Microbiologia.1963; 11: 167-171. Disponível em: 〈http://iah.iec.pa.gov.br/iah/fulltext/memo_iec/v7p175-178.pdf >. Acesso em novembro de 2014.

9. Clarke DH, Casals J. Technique for hemagglutination and hemagglutination inhibition with arthropodborne viruses. Am J Trop Med Hyg. 1958; 7: 561-573. Disponível em: <http://europepmc.org.scihub.org/abstract/MED/13571577 >. Acesso em novembro de 2014.

10. Rodrigues SG, Oliva OP, Araújo FAA, Martins LC, Chiang JO, Henriques DF, et al. Epidemiology of Saint Louis encephalitis virus in the Brazilian Amazon region and in the State of Mato Grosso do Sul, Brazil: elevated prevalence of antibodies in horses. Rev Pan-Amaz Saude. 2010;1: 81-86. Disponível em:

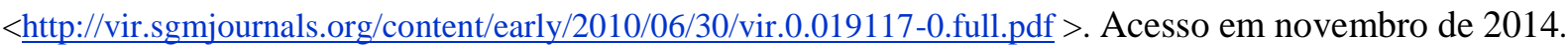

11. Ayres M, Ayres JRM, Ayres DL, Santos AS. BioEstat 5.0-Aplicações Estatísticas nas Áreas das Ciências Biológicas e Médicas. Belém: sociedade civil mamirauá, Brasília CNPq, 2007. Disponível em: $<$ http://www.mamiraua.org.br/pt-br/downloads/programas/bioestat-versao-53/ >. Acesso em novembro de 2014.

12. Ross CE, Dubovi EJ, Donis RO. Herd problem of abortions and malformed calves attributed to bovine viral diarrhea. Journal of the American Veterinary Medical Association. 1986; 188: 618-619. Disponível em: 〈http://www.ncbi.nlm.nih.gov/pubmed/3957770?dopt=Abstract $>$. Acesso em novembro de 2014.

13. Pavarini SP, Sonne L, Antoniassi NAB, Santos ASO, Pescador CA, Corbellini LG, et al. Anomalias congênitas em fetos bovinos abortados no Sul do Brasil. Pesquisa Veterinária Brasileira. 2008; 28: 149-154. Disponível em: <http://www.scielo.br/scielo.php?pid=S0100-736X2010001000002\&script=sci_arttext.

14. Mohamed M, Mclees A, Elliott RM. Viruses in the Anopheles A, Anopheles B, and Tete Serogroups in the Orthobunyavirus genus (family Bunyaviridae) do not encode a NSs protein. Journal of Virology, 83: 7612-7618, 2009. Disponível em: http://jvi.asm.org.sci-hub.org/content/83/15/7612.short>. Acesso em novembro de 2014.

15. Monath TP, Sabatini MS, Pauli R, Daffner JF, Mitchell CJ, Bowen GS, et al. Arbovirus investigation in Argentina, 1977-1980. American Journal of Tropical Medicine and Hygiene. 1985; 34: 966-975. Disponível em: <http://europepmc.org.sci-hub.org/abstract/MED/2863991>. Acesso em novembro de 2014.

16. Calisher CH, Oro JGB, Lord RD, Sabattini MS, Karabatsos N. Kairi Virus Identified from a Febrile Horse in Argentina. The American Jounal of Tropical Medicine and Hygiene. 1988; 39: 519-521. Disponível em: 〈http://europepmc.org.sci-hub.org/abstract/med/3143273 >. Acesso em novembro de 2014.

17. Emmons RW, Woodie JD, Laub RL, Oshiro LS. Main Drain virus as a cause of equine encephalomyelitis. Journal of the American Veterinary Medical Association. 1983; 183: 555-8. Disponível 
em:

<http://www.researchgate.net/publication/16781770_Main_Drain_virus_as_a_cause_of_equine encephalomyelitis?ev= pub_cit>. Acesso em novembro de 2014.

18. Edwards JF, Karabatsos N, Collisson EW, Bermejillo AC. Ovine Fetal Malformations Induced by in Utero Inoculation with Main Drain, San Angelo, and Lacrosse Viruses. Am J Trop Med Hyg. 1997; 56: 171176. Disponível em: 〈http://europepmc.org.sci-hub.org/abstract/med/9080876 >. Acesso em novembro de 2014.

19. Spence L, Jonkers AH, Grant LS. Arboviruses in the Caribbean Islands. Prog. Med. Virol. 1968; 10:415486. Disponível em: 〈http://www.ncbi.nlm.nih.gov/pubmed/?term=4886890 >. Acesso em novembro de 2014.

20. San Martins C, Mackenzie RB, Trapido H, Barreto R, Mullanax CH, Gutierrez E, et al. Encephalitis equina venezuelana en Colombia. Bol. Ofic. Sanit. Panamer. 1973; 74: 108-137. Disponível em: <http://hist.library.paho.org.sci-hub.org/spanish/Bol/v74n2p108.pdf >. Acesso em novembro de 2014.

21. Sabattini MS, Shope RE, Vanella JM. Serological survey for arboviruses in Cordoba Province, Argentina. Amer. J. trop. Med. Hyg. 1965; 14: 1073-1078. Disponível em: <http://www.ajtmh.org/content/14/6/1073.long >. Acesso em novembro de 2014.

22. Iversson LB, Silva RAMS, Travassos da Rosa APA, Barros VLRS. Circulation of Eastern Equine Encephalitis, Wessern Equine Encephalitis, Ilhéus, Maguari and Tacaiuma viruses in equines of the brazilian pantanal, South America. Revista do Instituto de Medicina Tropical. 1993; 35: 355-359. Disponível em: $<$ http://www.scielo.br/scielo.php?pid=S0036-46651993000400009\&script=sci_arttext $>$. Acesso em novembro de 2014.

23. Billecocq A, Vazeille-Falcoz M, Rodhain F, Bouloy M. Pathogen-specific resistance to Rift Valley fever virus infection is induced in mosquito cells by expression of the recombinant nucleoprotein but not NSs nonstructural protein sequences. Journal of General Virology. 2000; 81: 2161-2166. Disponível em: http://vir.sgmjournals.org/content/81/9/2161.full.pdf + html

24. Causey OR, Shope RE. Icoaraci, a new virus related to Naples phlebotomus fever virus (29862). Proceedings of the Society for Experimental Biology and Medicine. 1965; 118: 420-421. Disponível em: <http://ebm.sagepub.com/content/118/2/420.short >. Acesso em novembro de 2014.

25. Kurogi H, Inaba Y, Takahashi E, Sato K, Satoda K, Goto Y, et al. Congenital abnormalities in newborn calves after inoculation of pregnant cows with Akabane virus. Infection and Immunity. 1977; 17: 338-343. Disponível em:< http://sci-hub.org/downloads/a431/10.0000@iai.asm.org@iai@17@2@338.pdf

26. Parsonson IM, Della-Porta AJ, Snowdon WA. Congenital abnormalities in newborn lambs after infection of pregnant sheep with Akabane virus. Infecction and Immunity. 1977; 15: 254-262 Disponível em: http://scihub.org/downloads/6e85/10.0000@iai.asm.org@iai@15@1@254.pdf >. Acesso em novembro de 2014.

27. Nicolson TB, Nettleton PF, Spence JA, Calder KH. High incidence of abortions and congenital deformities of unknown aetiology in a breed herd. Veterinary Record. 1985; 116: 281-284. Disponível em: 〈http://europepmc.org.sci-hub.org/abstract/med/3992830 >. Acesso em novembro de 2014.

28. Schmidt V, Oliveira RT. Artrogripose em caprino: Relato de caso. Arquivo Brasileiro de Medicina Veterinária e Zootecnia. 2004; 56: 38-440. Disponível em: <http://www.lume.ufrgs.br/bitstream/handle/10183/67856/000871451.pdf?sequence=1 $>$. Acesso em novembro de 2014.

29. Borges AS, Mendes LCN, Vasconcelos R, Alves ALG, Rodrigues CA. Espinha bífida e mielodisplasia em ruminantes: relato de caso. Arquivo Brasileiro de Medicina Veterinária e Zootecnia. 1997; 49: 685-692. Disponível em: $\quad$ http://base.repositorio.unesp.br/bitstream/handle/11449/65237/2-s2.00031378076.pdf? sequence=1\&isAllowed=y >. Acesso em novembro de 2014 . 